\title{
LA COMUNICACIÓN DE LA EMERGENCIA EN ERUPCIONES VOLCÁNICAS EN CHILE Y SU IMPACTO DURANTE LA PANDE- MIA DEL COVID-19
}

Cristian Farías ${ }^{*}$

Chile es un país donde la norma es tener erupciones volcánicas, con varias de ellas siendo muy explosivas. Hoy podemos aprender de sus complejidades, y los errores en torno a la comunicación de emergencia en ellas, para poder mejorar la situación de la pandemia del SARS-CoV-2 en Chile.

En las semanas previas a la Navidad de 1988 el magma debajo del volcán Lonquimay, localizado en el sur de Chile, estaba ascendiendo. Se iba abriendo camino, generando un enjambre de sismos muy notorios, que pusieron a toda la zona cercana en alerta. Cuando finalmente comenzó la erupción, en un sistema al que no se le había visto tan activo en mucho tiempo, las explosiones no se dieron en el cráter principal del volcán, sino que en un cordón fisural al Este de él, creando un nuevo cono, llamado Navidad. La erupción, que no fue muy explosiva, duró más de un año, y marcó la primera vez que en Chile se podía ver y registrar el nacimiento de un volcán. Ya que llegar al lugar era relativamente sencillo, atrajo el interés de muchas personas. En la época no había una red de monitoreo volcánico, por lo que académicos de la Universidad de Chile y de la Universidad de la Frontera instalaron sismómetros en la zona, para poder seguir la actividad del volcán. Era un escenario muy nuevo para los habitantes del territorio, que con el tiempo verían como la columna de ceniza se convertía en su principal amenaza. Dado que esta puede producir problemas a la salud (se habló en su momento de hasta un daño neurológico), la autoridad sanitaria recomendó usar mascarillas, y evitar salir de las casas. Además, la columna de ceniza contaminó los pastos que comía el ganado debido a su alta concentración de flúor, causando la muerte de muchos animales. Los mismos que eran una parte importante de la economía de la zona. El invierno de 1989 se volvió muy duro, con un problema sanitario y económico. Los niños abandonaron el pueblo de Lonquimay, siendo enviados a distintos internados de ciudades cercanas. Esta separación familiar fue muy dura, y no duró demasiado, pero sí fue una experiencia que marcó la vida de muchos allí.

Si algunas de estas experiencias suenan familiares hoy, no es casualidad. En Chile hemos tenido instancias donde comunidades han pasado por momentos de mucha tensión, viendo sus vidas fuertemente afectadas. Otro caso icónico es el de Chaitén, donde la potente erupción del volcán del mismo nombre del 2008 forzó la evacuación de sus habitantes. El exilio de ellos, el fallido intento de la construcción de una 'Nueva Chaitén' $10 \mathrm{~km}$ al norte, y la reconstrucción del pueblo en una zona muy expuesta a las amenazas de origen volcánico, se han estudiado ampliamente. En todo ese proceso, la desconfianza desde la comunidad hacia el Estado, debido al abandono de parte de él, llevó a una serie de malas decisiones desde el punto de vista de la Gestión del Riesgo de Desastres (GRD), concluyendo con muchos viviendo en un estado peor que el de antes. Durante todo el proceso, la vocería del gobierno de turno estuvo muy basada en mensajes fuertes, donde las órdenes eran lo fundamental, dejando relegada la empatía hacia las personas que habían perdido su forma vida para otro momento. Esto último ha sido transversal en el país, y lo hemos visto después de terremotos, aluviones, y otros fenómenos destructivos. Ha resultado ser útil cuando se está en las primeras fases de una emergencia, pero no después. Y ciertamente no es útil hoy en plena crisis sanitaria.

\author{
1. Departamento de \\ Obras Civiles y Geología, \\ Universidad Católica de \\ Temuco, Temuco, Chile. \\ *Autor de correspondencia: \\ cristian.farias@uct.cl

\section{RECIBIDO} \\ 10 de junio de 2020

\section{PUBLICADO} \\ 1 de julio de 2020

\section{Formato cita} \\ Recomendada (APA): \\ Farías, C. (2020). La \\ comunicación de la \\ emergencia en erupciones \\ volcánicas en Chile y \\ su impacto durante la \\ pandemia del COVID-19. \\ Revista de Estudios \\ Latinoamericanos sobre \\ Reducción del Riesgo de \\ Desastres REDER, 4(2), \\ 123-124.
}

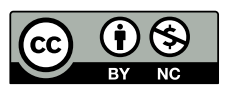

Todos los artículos publicados en REDER siguen una política de Acceso Abierto y se respaldan en una Licencia CreativeCommons Atribución-NoComercial 4.0 Internacional.

\section{Revista de Estudios} Latinoamericanos sobre Reducción del Riesgo de Desastres (REDER)

Diseño: Lupe Bezzina Tipografía: Hospital 
Hoy estamos en medio de una pandemia que nos encontró en uno de los puntos más bajos de confianza desde la ciudadanía hacia el Gobierno de Chile. Además, la estrategia para mitigar el impacto de la pandemia ha venido acompañada de una comunicación muy deficiente, donde se ha pasado desde un triunfalismo extremo, a mensajes contradictorios en las últimas semanas, que han fallado en instalar la gravedad de la situación de la pandemia en el territorio. Hoy necesitamos que la palabra 'Desastre' comience a aparecer, para poder hablar de la pandemia, sus consecuencias, y la estrategia que estamos tomando como país. Ya experimentamos el daño que generó el hablar de 'marejadas' el 27 de Febrero del 2010, después del terremoto Mw 8.8 que ocurrió ese día, cuando en realidad estábamos teniendo un tsunami. Pero además necesitamos hablar, de forma empática, de las complejidades que tenemos al frente. Cuando ocurrieron las erupciones de los volcanes Lonquimay y Chaitén (así como todas las demás), no podíamos predecir como iba a continuar la situación con cada uno de ellos. No solo por falta de un monitoreo adecuado en su momento (1988 y 2008), sino que también por la naturaleza impredecible de muchos procesos volcánicos. Sin embargo, y pese a que la comunicación en esos casos también tuvo muchos altibajos -en especial cuando la erupción ya había terminado o cuando los primeros pulsos habían concluido-, hemos logrado comenzar a hablar de escenarios probables, para poder tener una idea de qué enfrentaremos en el futuro.

Para poder evitar una catástrofe de proporciones históricas debemos poder analizar lo que ha ocurrido antes. Las crisis con las erupciones volcánicas nos muestran que la desconfianza es fatal, y que la comunicación empática es fundamental. Además, nos muestran que es posible hablar de escenarios, para poder poner el énfasis en cuales son las medidas que podemos tomar como ciudadanos, para que entre todos podamos mitigar el impacto que tiene una pandemia en nuestras vidas. Es necesario hacer un correlato entre cuál es el impacto esperado de una medida que se tome, y cuáles son los escenarios que se pueden dar, dependiendo de lo que las personas decidan hacer. Es importante tomarse el tiempo y utilizar los recursos en comunicar de forma sencilla todo esto, para que cualquier persona pueda entender mejor qué está pasando, por muy terrible que sea. Así podremos comenzar a generar confianza, y ayudaremos a mejorar la participación de la ciudadanía en todo el proceso.

Está en nosotros.

\section{AUTOR}

Cristian Farías. Director del Departamento de Obras Civiles y Geología de la Universidad Católica de Temuco y Profesor Asistente de la misma casa de estudios. Licenciado y Magíster en Ciencias con Mención en Física en la Universidad de Chile, y Doctor (Dr. rer. nat.) en Geofísica en la Universidad de Bonn, Alemania. Investigador del Centro de Investigación de Evaluación de Riesgos y Mitigación de Procesos Geológicos, GeoKimün, en riesgo de desastres y comunicación científica. 